\title{
Comparación de protocolos de extracción de ADN con muestras de aleta y larva de peces: extracción modificada con cloruro de sodio
}

\author{
Nelson M. Lopera-Barrero', Jayme A. Povh, Ricardo P. Ribeiro, \\ Patricia C. Gomes, Carolina B. Jacometo y Taís da Silva Lopes \\ Departamento de Zootecnia, Programa de Pós-Graduação em Zootecnia, \\ Universidade Estadual de Maringá, Grupo de Pesquisa PEIXEGEN, Av. Colombo, 5790, \\ CEP 87020-900, Maringá, PR, Brazil
}

\begin{abstract}
N.M. Lopera-Barrero, J.A. Povh, R.P. Ribeiro, P.C. Gomes, C.B. Jacometo, and T. da Silva Lopes. Comparison of DNA extraction protocols of fish fin and larvae samples: modified salt (NaCl) extraction. 2008. Cien. Inv. Agr. 35(1):77-86. The use of appropriate sampling methods, the type of tissue or sample and the use of viable DNA extraction protocols are critical issues in studies based on PCR. In an attempt to identify a simple, reproducible, inexpensive and non-toxic method for obtaining high quality and quantity genomic DNA from fish fin and larvae samples, modified salt extraction protocol and modified phenol-chloroform extraction protocol were compared. The samples obtained from different fish species (Brycon orbignyanus, Piaractus mesopotamicus, Oreochromis niloticus, Leporinus elongatus and Prochilodus lineatus) using salt extraction showed good DNA quality and quantity (DNA/RNA relationship 1.8-2.2). These DNA samples were successfully used in the amplification of RAPD (Random Amplified Polymorphic DNA) and microsatellite molecular markers, demonstrating the same effectiveness of this protocol in comparison with modified phenol-chloroform extraction protocol. This DNA extraction procedure constitutes an alternative and efficient replacement for previous protocols for improving fish molecular studies.
\end{abstract}

Key words: Fish studies, genetic research, microsatellites, PCR amplification, RAPD.

\section{Introducción}

El uso de marcadores moleculares, por ejemplo RAPD (Random Amplified Polymorphic DNA) y microsatélites, permiten que el análisis del potencial genético de un pez, de una comunidad o una población sea determinada con mayor precisión, antes de la expresión de su fenotipo (Liu y Cordes, 2004). De este modo se puede estimar la diversidad genética, necesaria para estudiar practicas de manejo y conservación de peces, inclusive para aquellas especies en riesgo de extinción (Lopera-Barrero et al., 2006). Sin embargo, la viabilidad de estos estudios es

Recibido 26 julio 2007. Aceptado 08 octubre 2007. ${ }^{1}$ Dirigir correspondencia a N.M. Lopera-Barrero:

nelson.peixegen@gmail.com frecuentemente limitada por la dificultad de aislar ADN, en cantidad y calidad suficiente, desde pequeñas muestras de tejidos (Yue y Orban, 2001; Wasko et al., 2003; Aranishi, 2006).

El uso de apropiados métodos de muestreo, el tipo de tejido y la utilización de protocolos viables de extracción del ADN son puntos críticos en estudios basados en PCR. En peces, la utilización de aletas (Nam et al., 2003; Wasko et al., 2003, Lopera-Barrero et al., 2006), sangre (Cummings y Thorgaard, 1994), escamas (Adcock et al., 2000; Sire et al., 2000; Yue y Orban, 2001; Wasko et al., 2003), células bucales (Livia et al., 2006), óvulos (Aranishi, 2006) y músculo (Weber et al., 2003; Chakraborty et al., 2006) requiere de varios protocolos, donde la utilización de Chelex 100 
(Sigma, EUA), silica, micro-wave, nitrógeno líquido, fenol-cloroformo y sal común han sido bastante utilizados.

El uso del protocolo de extracción con fenolcloroformo ha sido el método más usado para obtener ADN genómico de peces. Estos protocolos tienen buenos resultados para muestras de diversos orígenes. Sin embargo, es un método lento, laborioso y contaminante (Yue y Orban, 2001). La extracción de ADN usando el protocolo con sal común $(\mathrm{NaCl})$ es una alternativa simple, fácil, rápida y no contaminante que permite obtener ADN de buena calidad, en cantidades suficientes, desde muestras de tejido de peces.

El propósito de este estudio fue obtener un método simple, reproducible, económico y no contaminante para la obtención de ADN destinados a estudios con marcadores moleculares RAPD y microsatélites en peces. Con este objetivo se comparó un protocolo modificado de extracción con sal común $(\mathrm{NaCl})$ con un protocolo modificado de extracción con fenol-cloroformo en muestras de aleta y larva de pez.

\section{Materiales y métodos}

\section{Material biológico y protocolos}

Muestras (aproximadamente 200-300 mg) de aletas caudales y larvas se obtuvieron desde cinco individuos de diferentes especies de peces (Brycon orbignyanus, Piaractus mesopotamicus, Oreochromis niloticus, Leporinus elongatus y Prochilodus lineatus), acondicionadas en micro-tubos Eppendorf con etanol absoluto y conservadas en congelador a $-20^{\circ} \mathrm{C}$. Se comparó un protocolo modificado de extracción de ADN con sal común $(\mathrm{NaCl})$ (Aljanabi y Martinez, 1997) con un protocolo modificado de extracción con fenol-cloroformo (Bardakci y Skibinski, 1994). En cada protocolo de extracción se incluyó tratamientos con y sin ARNsa.

Protocolo modificado de extracción con sal común. Muestras de aletas de peces y larvas (entera) en micro-tubos Eppendorf se trataron con $550 \mu \mathrm{L}$ de solución tampón de lisis $(50 \mathrm{mM}$ de Tris-HC1, pH 8.0, $50 \mathrm{mM}$ de EDTA, $100 \mathrm{mM}$ de $\mathrm{NaC} 1$ ) más $1 \%$ de SDS y $7 \mu \mathrm{L}$ de $200 \mu \mathrm{g} \cdot \mathrm{mL}$ ${ }^{1}$ de proteinasa $\mathrm{K}$. Inmediatamente se incubó en un baño termoregulado a $50^{\circ} \mathrm{C}$ por $12 \mathrm{~h}$. Luego, se adicionó $600 \mu \mathrm{L}$ de $\mathrm{NaCl} 5 \mathrm{M}$ a cada muestra antes de centrifugar por $10 \mathrm{~min}$ a $12000 \mathrm{rpm}$. El sobrenadante se transfirió a micro-tubos nuevos, donde se precipitó el ADN con 700 $\mu \mathrm{L}$ de etanol absoluto frío y posteriormente se incubó a $-20^{\circ} \mathrm{C}$ por $2 \mathrm{~h}$. Las muestras de ADN fueron centrifugadas, lavadas con $700 \mu \mathrm{L}$ de etanol 70\% y resuspendidas en tampón TE (10 $\mathrm{mM}$ de Tris pH 8.0 y $1 \mathrm{mM}$ de EDTA) $(80 \mu \mathrm{L}$ para aletas y $35 \mu \mathrm{L}$ para larvas) y luego tratado con $30 \mu \mathrm{g} \cdot \mathrm{mL}^{-1}$ de ARNsa e incubado en baño de agua por $40 \mathrm{~min}$ a $37^{\circ} \mathrm{C}$. El ADN obtenido se conservó a $-20^{\circ} \mathrm{C}$.

Protocolo modificado de extracción con fenolcloroformo. Muestras de aletas de peces y larvas (entera) colocadas en micro-tubos, se trataron con $550 \mu \mathrm{L}$ de solución tampón de lisis (50 mM de Tris- $\mathrm{HC} 1 \mathrm{pH} 8.0,50 \mathrm{mM}$ de EDTA, $100 \mathrm{mM}$ de $\mathrm{NaC} 1$ ) más $1 \%$ de SDS y $7 \mu \mathrm{L}$ de $200 \mu \mathrm{g} \cdot \mathrm{mL}^{-1}$ de proteinasa $\mathrm{K}$ y se incubaron en baño termoregulado a $50^{\circ} \mathrm{C}$ por $12 \mathrm{~h}$. Luego, el ADN fue purificado con dos extracciones separadas de fenol $(250 \mu \mathrm{L})$ y tres extracciones separadas de cloroformo $(250 \mu \mathrm{L})$. El ADN obtenido se precipitó con $750 \mu \mathrm{L}$ de etanol absoluto frío y con $300 \mu \mathrm{L}$ de acetato de sodio. En seguida se incubó en un congelador a $-20^{\circ} \mathrm{C}$ por $2 \mathrm{~h}$. Posteriormente, las muestras de ADN se centrifugaron con $700 \mu \mathrm{L}$ de etanol al $70 \%$, se resuspendieron en tampón TE $(10 \mathrm{mM}$ de Tris pH 8.0 y $1 \mathrm{mM}$ de EDTA) $(80 \mu \mathrm{L}$ para aletas y $35 \mu \mathrm{L}$ para larvas), antes de tratarlas con $30 \mu \mathrm{g} \cdot \mathrm{mL}^{-1}$ de ARNsa. El ADN obtenido se incubó en baño termoregulado a $37^{\circ} \mathrm{C}$ por 40 min y finalmente se conservó a $-20^{\circ} \mathrm{C}$.

\section{Integridad y cuantificación del ADN}

La integridad del ADN se verificó por electroforesis horizontal utilizando un gel de agarosa $1 \%, 70 \mathrm{~V}$ por $60 \mathrm{~min}$, en tampón $1 \mathrm{x}$ TBE $(500 \mathrm{mM}$ de Tris-HC1, $60 \mathrm{mM}$ de ácido bórico y $83 \mathrm{mM}$ de EDTA). Un control negativo con todos los reactivos, pero sin ADN molde, se usó para determinar una posible contaminación de las muestras amplificadas. El gel se tiñó con bromuro de etidio $\left(0,5 \mu \mathrm{g} \cdot \mathrm{mL}^{-1}\right)$ por $30 \mathrm{~min} \mathrm{y}$ 
se capturó la imagen con el sistema fotográfico EDAS (Kodak 1D Image Analysis 3.5, NY, EUA). La cantidad y calidad del ADN obtenido se determinó con un espectrofotómetro Shimadzu (UV 1601, Shimadzu, Columbia, EUA) con una absorbancia de 260/280 nm. Para esto, muestras de ADN molde se diluyeron a $10 \mathrm{ng} \cdot \mu \mathrm{L}^{-1}$ en tampón TE. La electroforesis se realizó en gel de agarosa al $1 \%, 70 \mathrm{~V}$ por 60 min, en tampón 1x TBE. El gel fue marcado con bromuro de etidio y la imagen se capturó con el sistema fotográfico EDAS de Kodak.

\section{Amplificación por RAPD}

Muestras de ADN de todas las especies extraídas por ambos protocolos fueron utilizadas en la amplificación de un partidor específico (OPW19, Operon Technologies Inc. Alameda, CA, EUA) (Cuadro 1) mediante el marcador molecular RAPD (Williams et al., 1990). Se amplificó un volumen de reacción de $15 \mu \mathrm{L}$, usando tampón Tris- $\mathrm{KCl}$ (Tris-HC1 $20 \mathrm{mM} \mathrm{pH}$ 8,4 y $\mathrm{KC1} 50 \mathrm{mM}$ ), 2,5 mM de $\mathrm{MgCl}_{2}, 100 \mathrm{ng}$ de partidor, 0,2 $\mathrm{mM}$ de cada dNTP, una unidad de Platinum Taq ADN Polimerasa (Invitrogen, EUA) y 5 o $10 \mathrm{ng}$ de ADN, para larvas y aletas, respectivamente. Las reacciones de RAPD fueron amplificadas en un termociclador Eppendorf Mastercycler Gradient (Eppendorf, NY, EUA) programado para 40 ciclos, con un paso inicial de desnaturalización a $94^{\circ} \mathrm{C}$ por 4 min y una extensión final a $72^{\circ} \mathrm{C}$ por 5 min. Cada ciclo consistió en 1 min a $94^{\circ} \mathrm{C} ; 1,5$ $\min$ a $40^{\circ} \mathrm{C}$ y $2 \min$ a $72^{\circ} \mathrm{C}$. La electroforesis horizontal se realizó en gel de agarosa al 1,5\%, $70 \mathrm{~V}$ por $4 \mathrm{~h}$, usando tampón 1x TBE. El gel se marcó con bromuro de etidio.

\section{Amplificación por microsatélites}

El ADN de P. mesopotamicus se amplificó en 20 $\mu \mathrm{L}$, con tampón 1xTris-KCl, 2,0 mM de $\mathrm{MgCl}_{2}$, $0,8 \mu \mathrm{M}$ del partidor Pme14 (forward y reverse) (Calcagnottoetal.,2001)(Cuadro1), conteniendo la mezcla $0,2 \mathrm{mM}$ de cada dNTP, una unidad de Platinum Taq ADN polimerasa y 10 o $20 \mathrm{ng}$ de ADN para larvas y aleta, respectivamente. Inicialmente el ADN se desnaturalizó a $94^{\circ} \mathrm{C}$ por 4 min y luego se realizaron 30 ciclos, cada uno consistiendo de $30 \mathrm{~s}$ de desnaturalización a $94^{\circ} \mathrm{C}, 30 \mathrm{~s}$ de apareamiento a $62^{\circ} \mathrm{C}$ y $60 \mathrm{~s}$ de extensión a $72^{\circ} \mathrm{C}$. Una extensión final a $72^{\circ} \mathrm{C}$ por $10 \mathrm{~min}$ fue incorporada en el perfil térmico. Las reacciónes fueron amplificadas en un termociclador Eppendorf Mastercycler Gradient. La electroforesis se realizó en gel de poliacrilamida al $10 \%$, en condiciones desnaturalizantes en tampón 1xTBE con un amperaje de $50 \mathrm{~mA}$ por $7 \mathrm{~h}$. Se tiñó con nitrato de plata (Bassam et al., 1991).

\section{Diseño y análisis estadísticos}

Los valores de concentración de ADN obtenidos en cada protocolo de extracción se analizaron estadísticamente para varianza de acuerdo con un diseño completamente al azar con cuatro repeticiones, empleando SAS (SAS Institute, Cary, NC, EUA).

\section{Resultados}

\section{Integridad}

El protocolo modificado de extracción con sal común permitió obtener un ADN íntegro a

Cuadro 1. Secuencias de los partidores usados en las amplificaciones con el marcador molecular RAPD y microsatélite. Table 1. Sequences of primers used in the amplifications with RAPDs and microsatellites.

\begin{tabular}{lccc}
\hline Marcador Molecular & Partidor & Secuencia & Referencia \\
\hline RAPD & OPW19 & 5' CAAAGCGCTC 3' & Operon Technologies \\
Microsatélite & Pme14 & 'F: 5' ACCGTTATGCCCTACCCTTC 3' & \\
& & 'R: 5' GCGTTCTAGACAGAACTCATGG 3' & Calcagnotto et al., 2001
\end{tabular}




\section{Tratadas con RNAsa (a)}

\section{Protocolo Fenol-Cloroformo}

\section{Protocolo Sal}

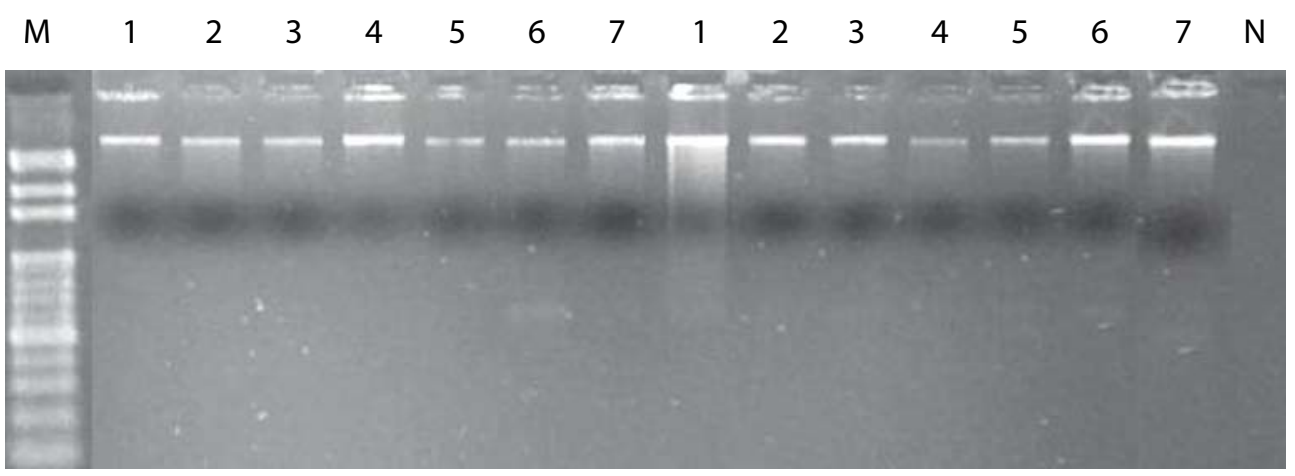

No tratadas con RNAsa (b)

\section{Protocolo Fenol-Cloroformo Protocolo Sal}

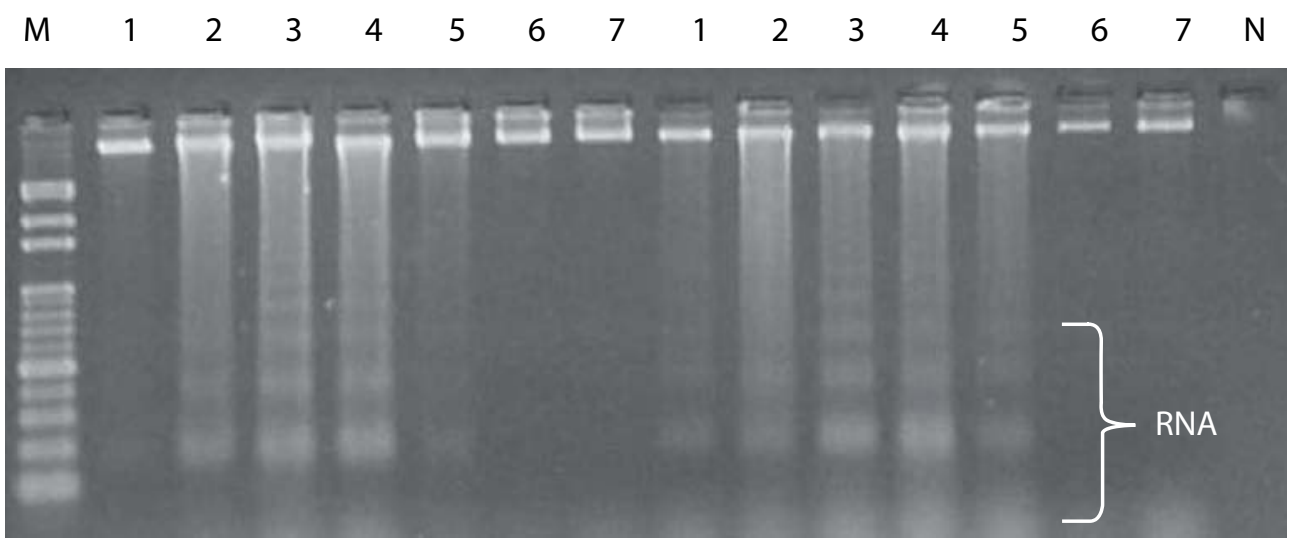

Figura 1. Comparación de la extracción de $\operatorname{ADN}$ de aletas $(1,2,3,4,5)$ y larva $(6$ y 7$)$ de peces para Brycon orbignyanus (1 y 7), Piaractus mesopotamicus (2), Oreochromis niloticus (3), Leporinus elongatus (4) y Prochilodus lineatus (5 y 6). M: marcador de peso molecular (100 bp). N: Control negativo.

Figure 1. Comparison of the DNA extraction of fish fins (1,2, 3, 4 and 5) and fish larvae (6 and 7) by Brycon orbignyanus (1 and 7), Piaractus mesopotamicus (2), Oreochromis niloticus (3), Leporinus elongatus (4) and Prochilodus lineatus (5 and 6). M: molecular weight marker (100 bp). N: Negative control.

partir de muestras de aleta y larva, sin signos de degradación o fragmentación y con una baja extracción de contaminantes (proteínas y ARN). Este resultado fue confirmado en el control negativo, que mostró ausencia de trazos y fragmentos en el gel, lo que fue indicativo de ausencia de contaminación (Figura 1). Adicionalmente, los valores de absorbancia a 280/260 $\mathrm{nm}$ mostraron la inexistencia de proteínas en exceso (ADN/proteína $=1,8$ a 2,2) (Cuadro 2). Esto, de acuerdo con Aljanabi y Martinez (1997), Wasko et al. (2003) y Ferrara et al. (2006) sugiere la presencia de ADN de buena calidad.

Las muestras tratadas con ARNsa mostraron un ADN libre de ARN, lo que contrastó con los resultados obtenidos en muestras sin tratar con ARNsa (Figura la y b), donde el ADN extraído mostró alta presencia de ARN, pudiendo interferir en la correcta cuantificación y amplificación del ADN. Estos resultados evidencian la efectividad del protocolo modificado de extracción con sal común y su similar 
Cuadro 2. Valores medios de pureza del ADN expresados en la razón de absorbancia 260/280, usando el protocolo modificado de extracción con sal (sal) y el protocolo modificado de extracción con fenol-cloroformo (F/C) para aletas y larvas de Brycon orbignyanus, Piaractus mesopotamicus, Oreochromis niloticus, Leporinus elongatus y Prochilodus lineatus.

Table 2. Mean values of DNA purity expressed in the 260/280 absorbance ratio, using modified salt extraction protocol (salt) and modified phenol-chloroform extraction protocol $(F / C)$ by fish fins and fish larvae of Brycon orbignyanus, Piaractus mesopotamicus, Oreochromis niloticus, Leporinus elongatus, and Prochilodus lineatus.

\begin{tabular}{|c|c|c|c|}
\hline \multirow[b]{2}{*}{ Muestras } & \multirow[b]{2}{*}{ Especies } & \multicolumn{2}{|c|}{$\begin{array}{l}\text { Protocolos de extracción absorbancia, } \\
260 / 280\end{array}$} \\
\hline & & Sal & $\mathrm{F} / \mathrm{C}$ \\
\hline \multirow[t]{5}{*}{ Aletas } & B. orbignyanus & 1,84 & 2,10 \\
\hline & P. mesopotamicus & 1,92 & 1,86 \\
\hline & O. niloticus & 1,88 & 1,94 \\
\hline & L. elongatus & 2,10 & 1,85 \\
\hline & P. lineatus & 2,19 & 2,11 \\
\hline \multirow[t]{2}{*}{ Larvas } & P. lineatus & 1,97 & 2,14 \\
\hline & B. orbignyanus & 1,83 & 1,86 \\
\hline
\end{tabular}

desempeño con el protocolo modificado de fenolcloroformo. No obstante, en ambos es necesaria la utilización de proteinasa $\mathrm{K}$ y de ARNsa.

\section{Cuantificación}

El protocolo de extracción tuvo un efecto significativo $(\mathrm{p}<0,01)$ en la concentración media de ADN extraída en muestras de $B$. orbignyanus, $P$. mesopotamicus, L. elongatus y $P$. lineatus, utilizando los protocolos modificados con sal común y fenol-cloroformo. Las muestras de $O$. niloticus no presentaron diferencias estadísticas (Figura 2). En muestras de aleta, usando el protocolo modificado de extracción con sal común fue posible extraer aproximadamente entre $420 \mathrm{ng} \cdot \mu \mathrm{L}^{-1}$ de ADN en $B$. orbignyanus y $360 \mathrm{ng} \cdot \mu \mathrm{L}^{-1}$ para $P$. lineatus, con promedios de $396 \mathrm{ng} \cdot \mu \mathrm{L}^{-1}$. En las muestras de larva se extrajo aproximadamente 140 ng $\cdot \mu \mathrm{L}^{-1}$ de ADN en P. lineatus y $170 \mathrm{ng} \cdot \mu \mathrm{L}^{-1}$ en $B$. orbignyanus. Cantidades menores de ADN se obtuvieron usando el protocolo de extracción con fenol-cloroformo (358 y $135 \mathrm{ng} \cdot \mu \mathrm{L}^{-1}$ para aleta y larva, respectivamente) (Figura 2).

\section{Amplificación}

Mediante el uso del marcador RAPD, el partidor OPW19 amplificó con éxito fragmentos en ambos protocolos modificados, utilizando muestras de aleta y larva en las cinco especies de peces utilizadas (Figura 3). De la misma forma, la amplificación del marcador molecular microsatélite con el partidor Pme14 utilizando el protocolo modificado con sal, presentó buenos resultados, siendo verificada con claridad la presencia de varios alelos (Figura 4).

\section{Discusión}

Este estudio demostró la efectividad del protocolo modificado de extracción con sal común desarrollado en este trabajo. Este es un método simple, reproducible, económico y no contaminante, posible de utilizar para la obtención de ADN a partir de muestras de aleta y larva de peces. Mediante la amplificación utilizando los marcadores moleculares RAPD y microsatélite, se confirmó su utilidad y reproducibilidad en estudios genéticos basados en PCR. Este protocolo de extracción puede substituir protocolos que utilizan elementos químicos contaminantes y peligrosos, como es el caso de protocolos con fenol-cloroformo. Cinco pasos fueron esenciales en el proceso de extracción con sal común: 1. Liberación de componentes celulares, 2. Eliminación de proteínas y lípidos, 3. Precipitación del ADN mediante la utilización de $\mathrm{NaCl}, 4$. Remoción del RNA y 5. Almacenaje.

De acuerdo con los resultados de este estudio, se demostró la necesidad de la utilización de la ARNsa durante la extracción de ADN. Esto permitió obtener muestras suficientemente purificadas de ADN para una correcta y segura amplificación, disminuyendo de esta forma 


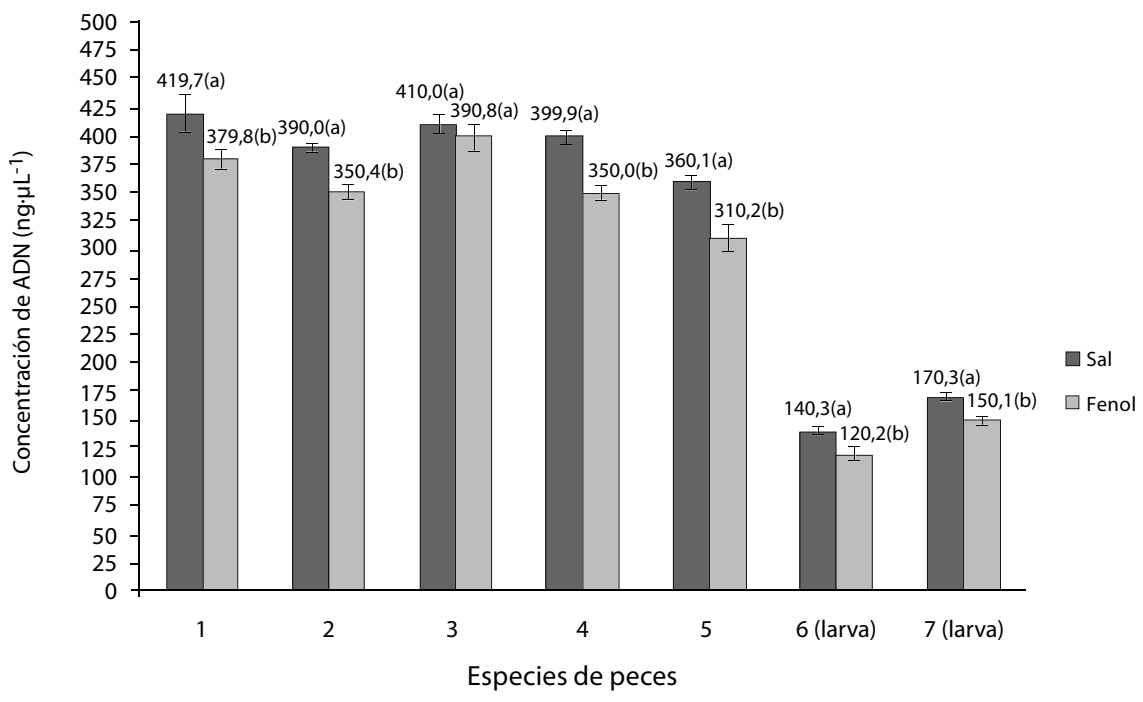

Figura 2. Valores medios y desvíos estándar (barras) de la concentración de $\mathrm{ADN}\left(\mathrm{ng} \cdot \mu \mathrm{L}^{-1}\right)$ obtenido de aletas y larvas de peces usando el protocolo modificado de extracción con sal y el protocolo modificado de extracción con fenol-cloroformo para Brycon orbignyanus (1 y 7), Piaractus mesopotamicus (2), Oreochromis niloticus (3), Leporinus elongatus (4) y Prochilodus lineatus (5 y 6).

Figure 2. Mean values and standard deviations (bars) of DNA extraction concentration (ng $\left.\cdot \mu L^{-1}\right)$ obtained in fish fins and fish larvae using modified salt extraction protocol and modified phenol-chloroform extraction protocol by Brycon orbignyanus (1 and 7), Piaractus mesopotamicus (2), Oreochromis niloticus (3), Leporinus elongatus (4) and Prochilodus lineatus (5 and 6).

falsos resultados (Wasko et al., 2003). Estos autores, investigando la extracción de ADN a partir de aletas de peces con el protocolo de fenol-cloroformo, definieron igualmente que el uso de una baja concentración de ARNsa puede provocar la obtención de ADN de baja calidad. Por tanto, es indispensable el uso de ARNsa en protocolos de extracción de muestras en peces. Por ejemplo, en la extracción modificada con sal común y con fenol-cloroformo propuesta en este estudio.

A diferencia de los resultados de Wasko et al. (2003), la temperatura de $50^{\circ} \mathrm{C}$ utilizada durante la digestión de las muestras (paso 1) no afectó la calidad y cantidad de ADN extraído en los protocolos modificados usados en este estudio (sal común y fenol-cloroformo). Wasko et al. (2003) detectó deficiencias a $50^{\circ} \mathrm{C}$, por lo que usó y recomendó una temperatura de $42^{\circ} \mathrm{C}$.

Todos los pasos del protocolo descritos anteriormente dependen directamente del tejido colectado, que en este caso fueron suficientes para una eficiente obtención de ADN. Según Taberlet et al. (1999) dos métodos diferentes de muestreo pueden ser utilizados: muestreo destructivo y no destructivo. En el muestreo destructivo los animales son sacrificados para la obtención de los tejidos necesarios en los análisis genéticos, lo que puede representar una gran desventaja si se está trabajando con grupos de reproductores o lotes pequeños. En el caso de estudios realizados en progenies, larvas se han utilizado exitosamente por su fácil colecta, gran cantidad y fácil almacenamiento.

En el muestreo no destructivo es innecesario el sacrificio del animal, permitiendo la colecta de muestras de tejidos internos (muestras invasoras, ej. sangre y músculo) y externos (muestras no invasoras, ej. aletas y escamas). Esta ventaja ha sido importante en la adaptación de esta metodología en protocolos 


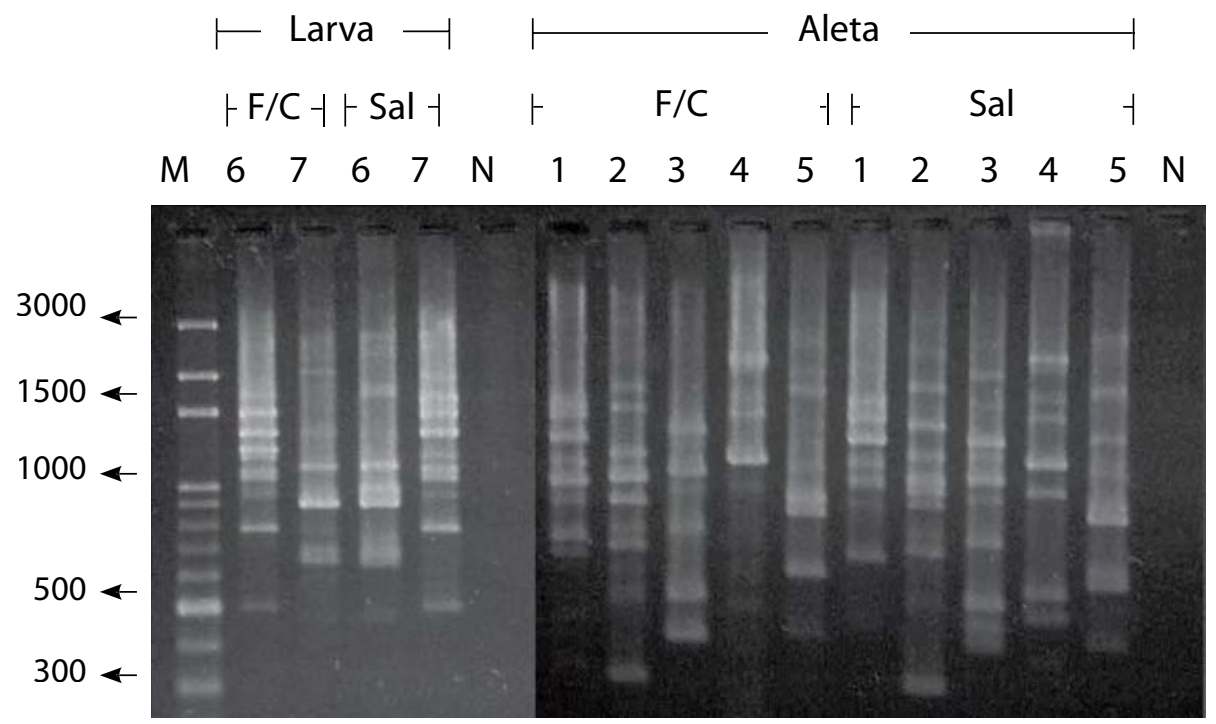

Figura 3. Comparación de la amplificación por el marcador RAPD de aletas (1, 2, 3, 4 y 5) y larvas de peces (6 y 7) usando el protocolo modificado de extracción con sal (Sal) y el protocolo modificado de extracción con fenol-cloroformo (F/C) para Brycon orbignyanus (1 y 7), Piaractus mesopotamicus (2), Oreochromis niloticus (3), Leporinus elongatus (4) y Prochilodus lineatus (5 y 6). M: marcador de peso molecular (100 pb). N: control negativo.

Figure 3. Comparison of the DNA amplification for RAPD marker of fish fins (1, 2, 3, 4 and 5) and fish larvae (6 and 7) using modified salt extraction protocol (Sal) and modified phenol-chloroform extraction protocol (F/C) by Brycon orbignyanus (1 and 7), Piaractus mesopotamicus (2), Oreochromis niloticus (3), Leporinus elongatus (4) and Prochilodus lineatus (5 and 6). M: molecular weight marker (100 bp). N: negative control.

de extracción de ADN, permitiendo un mejor confort y menor intervención en la fisiología y en el comportamiento del animal.

El ADN extraído a partir de larvas tuvo mejor calidad que el extraído a partir de muestras de aleta. Posiblemente esto se debió a la menor presencia de componentes celulares (proteína, lípidos, partículas de músculos), permitiendo la obtención de muestras de ADN más puras. Sin embargo, los resultados de una amplificación por RAPD y microsatélite se podrían afectar por la presencia del saco vitelino (reserva de substancias nutritivas, principalmente proteínas y lípidos, que nutre las larvas durante las primeras fases de vida). La presencia de estas substancias puede llegar a inhibir la acción de la Taq ADN polimerasa o formar quelato con magnesio, necesario para activar la enzima Taq durante la amplificación.

Lopera-Barrero et al. (2007) y Povh et al. (2007), estudiando lotes de P. mesopotamicus, constataron que para la amplificación de las larvas mediante los marcadores RAPD y microsatélite fue necesaria la reducción de la concentración del ADN y la utilización de una enzima más eficiente para su amplificación (Platinum Taq ADN Polimerasa), condiciones similares a las utilizadas en el presente estudio. Por esta razón, recomendamos que la colecta y extracción de larva se inicie después de la reabsorción del saco vitelino, lo que normalmente ocurre pasados tres días de nacidas.

Mayores cantidades de ADN se obtuvieron al utilizar el protocolo de extracción con sal común comparado con el protocolo de fenol-cloroformo (Figura 2). Es necesario resaltar que el volumen de ADN obtenido al final de la extracción con este protocolo (aproximadamente 50 y $80 \mu \mathrm{L}$ en muestras de larvas y aletas, respectivamente) es suficiente para al menos 50 amplificaciones de RAPD y 25 reacciones de microsatélite, siendo fácilmente almacenado en el congelador donde puede permanecer con una baja tasa de degradación. 


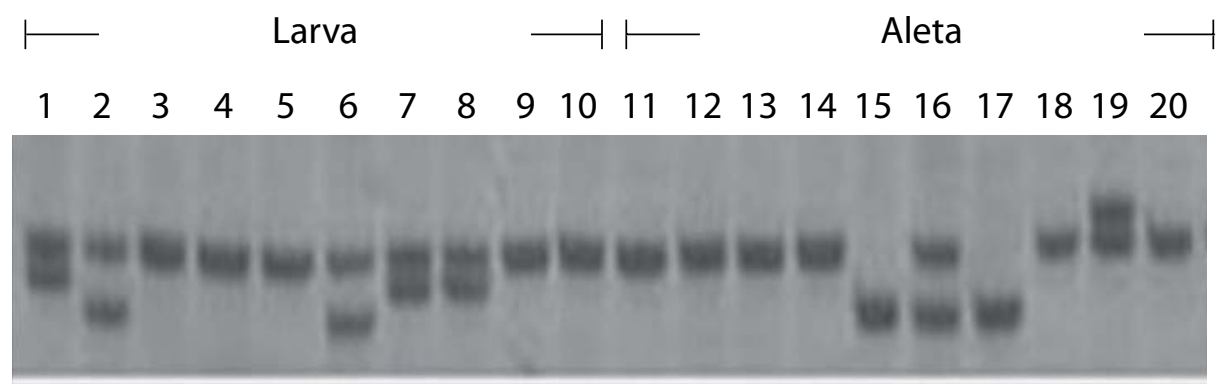

Figura 4. Amplificación de larvas (1 a 10) y aletas (muestras 11 a 20) de Piaractus mesopotamicus por el marcador molecular microsatélite, usando el protocolo modificado de extracción con sal.

Figure 4. Amplification of larvae (1 at 10 samples) and fins (11 at 20 samples) of Piaractus mesopotamicus for the microsatellite molecular marker, using the modified salt extraction protocol.

Al analizar las amplificaciones de RAPD y microsatélite realizadas utilizando el ADN extraído con el protocolo de sal común se obtuvieron amplificaciones claras y reproducibles (Figura 3 y 4). Esto demostró la efectividad del protocolo de extracción con sal común en la amplificación de estos marcadores. Según Liu e Cordes (2004), son los marcadores moleculares más usados en la actualidad en estudios genéticos de peces.

En este estudio, la aleta y larva de pez representaron una fuente de ADN tan conveniente como la de otros tipos de tejidos (músculo, hígado, sangre) presentando alta cantidad y calidad total de ADN aislado. Estos resultados coincidieron con Wasko et al., (2003) y Nam et al. (2003), quienes obtuvieron una buena extracción de ADN de aletas. Además, es destacable su facilidad de colecta y confiabilidad, en comparación con muestras de músculo o sangre. La aleta del pez y la larva son fuentes confiables de ADN y han sido usadas exitosamente en varios estudios poblacionales y taxonómicos (Vieira et al., 2005; Povh et al., 2005; Aho et al., 2006; Basavaraju et al., 2007), incluyendo el muestreo de descendencias de piscícolas o de aquellas usadas en programas de mejoramiento y repoblamiento (LoperaBarrero, 2005; Povh, 2007; Gomes, 2007).

\section{Resumen}

El uso de apropiados métodos de muestreo, tipo de tejido y la utilización de protocolos viables de extracción del ADN son aspectos críticos en estudios basados en PCR. Los métodos de extracción de ADN deben ser simples, reproducibles, económicos y no contaminantes. Este trabajo tuvo por objetivo comparar un protocolo modificado de extracción con sal común $(\mathrm{NaCl})$ y un protocolo modificado de extracción con fenol-cloroformo para la obtención de ADN genómico en alta cantidad y calidad desde muestras de aleta y larva de pez (Brycon orbignyanus, Piaractus mesopotamicus, Oreochromis niloticus, Leporinus elongatus y Prochilodus lineatus). Las muestras aisladas de diferentes especies de peces usando la extracción con sal común permitieron obtener ADN de buena calidad (relación DNA/RNA 1.8-2.2) y fue usado con éxito en la amplificación de los marcadores moleculares RAPD y microsatélite. Esto demostró la misma efectividad de la extracción de ADN con sal común en comparación con el protocolo modificado de extracción con fenolcloroformo. Este procedimiento de extracción de ADN constituye una alternativa y un reemplazo eficaz para los protocolos anteriores por mejorar los estudios moleculares en peces. 
Palabras clave: Amplificación por PCR, estudios de peces, investigación genética, microsatélites, RAPD.

\section{Literatura citada}

Adcock, G.L., B. Ramírez, L. Hauser, P. Smith, y G.R. Carvalho. 2000. Screening of DNA polymorphisms in samples of archived scales from New Zealand snapper. Journal of Fish Biology 56:1283-1287.

Aho, T., J. Rönn, J. Piironen y M. Björklund. 2006. Impacts of effective population size on genetic diversity in hatchery reared Brown trout (Salmo trutta L.) populations. Aquaculture 253:244248.

Aljanabi, S.M., y I. Martinez. 1997. Universal and rapid salt-extraction of high quality genomic DNA for PCR-based techniques. Nucleic Acids Research 25:4692-4693.

Aranishi, F. 2006. Single fish egg DNA extraction for PCR amplification. Conservation Genetics 7:153-156.

Bardakci, F. y D.O.F. Skibinski. 1994. Application of the RAPD technique in tilapia fish: species and subspecies identification. Heredity 73:117123.

Basavaraju, Y., D.T. Prasad, K. Rani, S.P. Kumar, U.D. Naika, S. Jahageerdar, P.P. Srivastava, D.J. Penman y G.C. Mair. 2007. Genetic diversity in common carp stocks assayed by random-amplified polymorphic DNA markers. Aquaculture Research 38:147-155.

Bassam, B.J., G. Caetano-Anollés y P.M. Gresshoff. 1991. A fast and sensitive silver staining for DNA in polyacrylamide gels. Analytical Biochemistry 196:80-83.

Calcagnotto, D., M. Russello y R. DeSalle. 2001. Isolation and characterization of microsatellite loci in Piaractus mesopotamicus and their applicability in other Serrasalminae fish. Molecular Ecology Notes 1:245-247.

Chakraborty, A., M. Sakai y Y. Iwatsuki. 2006. Museum fish specimens and molecular taxonomy: A comparative study on DNA extraction protocols and preservation techniques. Journal of Applied Ichthyology 22:160-166.

Cummings, A.S. y G.H. Thorgaard. 1994. Extraction of DNA from fish blood and sperm. Biotechniques 17:426.

Ferrara, G.B., B. Murgia, A.M. Parodi, L. Valisano, C. Cerrano, G. Palmisano, G. Bavestrello y M. Sara. 2006. The assessment of DNA from marine organisms via a modified salting-out protocol. Cellular and Molecular Biology Letters 11:155-160.
Gomes, P.C. 2007. Diversidade genética de três populações de piapara (Leporinus elongatus), utilizando marcadores moleculares. Dissertação (Mestrado em Zootecnia), Programa de PósGraduação em Zootecnia, Universidade Estadual de Maringá, Maringá, Brasil. 75 p.

Liu, Z.J. y J.F. Cordes. 2004. DNA marker technologies and their applications in aquaculture genetics. Aquaculture 238:1-37.

Livia, L., P. Antonella, L. Hovirag, N. Mauro y F. Panara. 2006. A nondestructive, rapid, reliable and inexpensive method to sample, store and extract high-quality DNA from fish body mucus and buccal cells. Molecular Ecology Notes 6:257-260.

Lopera-Barrero, N.M. 2005. Diversidade genética de populaçõesdepiracanjuba(Bryconorbignyanus) com a técnica de RAPD. Dissertação (Mestrado em Zootecnia), Programa de Pós-Graduação em Zootecnia, Universidade Estadual de Maringá, Maringá, Brasil. 45 p.

Lopera-Barrero, N.M., R.P. Ribeiro, R.N. Sirol, J.A. Povh, P.C. Gomes, L. Vargas y D.P. Streit Jr. 2006. Genetic diversity in piracanjuba populations (Brycon orbignyanus) with the RAPD (Random Amplified Polimorphic DNA) markers. Journal Animal Science 84:170.

Lopera-Barrero, N.M., D.P. Streit Jr, R.N. Sirol, R.P. Ribeiro, J.A. Povh, L. Vargas, P.C. Gomes, T. da S. Lopes, C.B. Jacometo y D.V. Blanck. 2007. Monitoramento da diversidade genética dos reprodutores e da progênie de Piaractus mesopotamicus obtidapelo sistema seminatural. P. 31-36-Genética. Em: I Congresso Brasileiro de Produção de Peixes Nativos de Água Doce, Brasil (Resumo).

Nam, Y.K., J.E. Park, K.K. Kim y D.S. Kim. 2003. A rapid and simple PCR-based method for analysis of transgenic fish using a restricted amount of fin tissue. Transgenic Research 12:523-525.

Povh, J.A. 2007. Avaliação da diversidade genética e do manejo reprodutivo do pacu, Piaractus mesopotamicus. Tese (Doutorado em Zootecnia), Programa de Pós-Graduação em Zootecnia, Universidade Estadual de Maringá, Maringá, Brasil. 75 p.

Povh, J.A., R.P. Ribeiro, R.N. Sirol, D.P. Streit Jr, H.L.M. Moreira, N.M. Lopera Barrero, L. Vargas, P.C. Gomes, C.B. Jacometo y T. da S. Lopes. 2007. Avaliação reprodutiva e da diversidade genética de Piaractus mesopotamicus no sistema seminatural. p. $7-$ 13-Genética. Em: I Congresso Brasileiro de Produção de Peixes Nativos de Água Doce, Brasil (Resumo).

Povh, J.A., H.L.M. Moreira, R.P. Ribeiro, A.P. Prioli, L. Vargas, D.V. Blanck, E. Gasparino y 
D.P. Streit Jr. 2005. Estimativa da variabilidade genética em tilápia do Nilo (Oreochromis niloticus) com a técnica de RAPD. Acta Scientiarum Animal Science 27:1-10.

Sire, J.Y., M. Girondot y O. Babiar. 2000. Marking zebrafish, Danio rerio (Cyprinidae), using scale regeneration. Journal of Experimental Zoology 286:297-304.

Taberlet, P., L.P. Waits y G. Luikart. 1999. Noninvasive genetic sampling: look before you leap. Trends in Ecology and Evolution 14:323327.

Vieira, V.P., R.P. Ribeiro, L. Vargas, H.L.M. Moreira, J.A. Povh y N.M. Lopera-Barrero. 2005. Avaliação da variabilidade genética de linhagens de tilápia do Nilo (Oreochromis niloticus) com o uso do marcador de RAPD. Revista Acadêmica Curitiba 3:41-49.
Wasko, A.P., C. Martins, C. Oliveira y F. Foresti. 2003. Nondestructive genetic sampling in fish. An improved method for DNA extraction from fish fins and scales. Hereditas 138:161-165.

Weber, L.P., P.S. Higgins, L.I. Carlson y D.M. Janz. 2003. Development and validation of methods for measuring multiple biochemical indices of condition in juvenile fishes. Journal of Fish Biology 63:637-658.

Williams, J.G., A.R. Kubelik, J. Livak, J.A. Rafalski y S.V. Tingey. 1990. DNA polymorphisms amplified by arbitrary primers are useful as genetic markers. Nucleic Acids Research 18:6531-6535.

Yue, G.H. y L. Orban. 2001. Rapid Isolation of DNA from Fresh and Preserved Fish Scales for Polymerase Chain Reaction. Marine Biotechnology 3:199-204. 